\title{
К.А. Михайленко
}

\section{ИЗДАТЕЛЬСТВО «ВОДОЛЕЙ» КАК ВАРИАНТ АВТОРСКОГО ИЗДАТЕЛЬСКОГО ПРОЕКТА}

\begin{abstract}
Статья посвящена интеграции категории проекта в область книгоиздания. На примере деятельности Е.А. Кольчужкина рассматривается концепция авторского издательского проекта. Освещзаются основные этапь деятельности «Водолея».

Ключевые слова: проект, региональное издательство и издатель, томская сре$\partial a$.
\end{abstract}

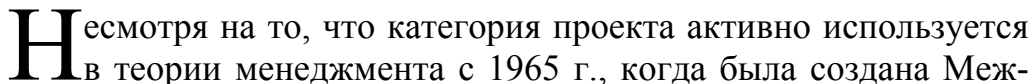
дународная ассоциация управления проектами (IPMA), в книгоиздательской сфере применение данного вида управления организацией встречается редко. Именно поэтому анализ работы издательства «Водолей» с точки зрения категории авторского проекта представляется актуальным и необходимым, тем более, если учесть, что освещение деятельности томского издателя Е.А. Кольчужкина в указанном контексте происходит впервые. В этом нами видится новизна и актуальность исследования.

Издательство «Водолей» было основано в 1991 г. в Томске Евгением Анатольевичем Кольчужкиным, который на тот момент имел высшее техническое образование, а также опыт работы заведующим редакционно-издательским отделом Томской областной научной библиотеки им. А.С. Пушкина ${ }^{1}$. Как и любой проект, проект Кольчужкина образовался и развивался в определенной среде, поэтому для его характеристики необходимо выделить ряд сопутствующих факторов:

Социально-культурное окружение.

Принципиально важной является характеристика круга чтения сибиряков конца XX в., связанная с эпохой перестройки и перехода региональных издательств к рыночным отношениям. В данный период, несмотря на сложные экономические и политические процессы, книга продолжает оставаться неотъемлемой частью жизни насе-

\footnotetext{
${ }^{1}$ См. об издательстве в [1].
} 
ления. Приоритетной была художественная литература. Второе и третье место по популярности у сибиряков занимали произведения о Великой Отечественной войне и так называемая развлекательная литература. В этот период увеличилось число посетителей библиотек. При этом, согласно статистике за 1985 г., интерес к литературе в Сибири был выше, чем в Центральной России. Востребованы были также издания общественно-политической тематики, историкомемуарные труды, специальная литература, а также книги по философии [2. С. 30-55].

С крахом тоталитарной политической системы и установлением нового законодательства разнообразная литература, ранее запрещенная, стала доступна для печати, а значит, и для читателя. Однако художественная, научно-популярная и специальная литература не утратила своего значения, несмотря на то, что развлекательная книга для досуга становилась все популярнее. Как можно видеть, сибиряков, особенно жителей такого интеллектуального города, как Томск, интересовал достаточно широкий спектр тем. Это создавало благоприятную возможность для местного книгоиздания с точки зрения рентабельности издательских проектов.

Международно-политическое окружение.

От «застоя» страна перешла к «перестройке», что означало начало постепенного освобождения печати от идейности и жесткого контроля. Благодаря самиздату, население страны, и в частности Сибири, открывало для себя запрещенные произведения, но данные издания не могли в полной мере удовлетворить читательский спрос. Однако уже в начале 90-х гг., когда Советский Союз перестал существовать, на читателей обрушилась вся та литература, которая долгое время удерживалась цензурой. Это было связано не только с изменениями в политическом строе, но и, как следствие, с закономерными процессами, происходившими в книжной торговле. Так, в этот период наблюдалось обособление книжной торговли по регионам, создание издательствами собственных каналов распространения, появление книготорговых сетей $[3,4]$. Не менее благоприятно это время было и для издателя с точки зрения свободы печати, но вместе с тем и сложное, так как в стране стало издаваться все, что только можно. Поэтому, достаточно быстро удовлетворив читательский спрос, местное книгоиздание столкнулось с перенасыщением рынка, конкуренция на котором становилась все жестче. 
Именно в это время появляется авторский проект Кольчужкина, схожий с такими проектами Центра, как издательства «Вагриус», «Захаров» или «Слово/Slovo». «Водолей» стал примером авторского мультипроекта на региональной почве, подпроекты которого объединены единой концепцией, тематикой, миссией и временностью. При этом под мультипроектом понимается «комплексный проект, состоящий из ряда монопроектов и требующий применения многопроектного управления» [4. С. 37]. В этом смысле авторский проект Кольчужкина представляет собой концепт, который объединяет все выпущенные им издания. Миссия, цель, культурный опыт - все это способствовало его реализации.

В переломные для страны годы «Водолей» стал практически первым частным негосударственным издательством в сибирском городе ${ }^{1}$. Создавая свое дело, Кольчужкин ставил целью следовать направлению, начатому символистскими издательствами начала $\mathrm{XX}$ в. - «Скорпион», «Мусагет», «Оры» - «отсюда и название: если был “Скорпион”, почему бы не возникнуть духовно родственному “Водолею”» [1]. Напомним, что издательство «Скорпион» стремилось к тому, чтобы удовлетворить спрос на декадентскую литературу и сформировать свою читательскую аудиторию. Оно также способствовало объединению символистов. Издательство «Мусагет» же было кружком единомышленников, клубом, где бывала творческая интеллигенция. Его издания отражали высокую культуру редакционной подготовки, однако с ведением дел у «Мусагета» были проблемы, возможно, потому, что оно позиционировало себя как некоммерческое. Все перечисленные издательства серьезно подходили к отбору текстов, который в свою очередь был напрямую связан с их идейной позицией.

Важно, что обращение именно к этому направлению было обусловлено не только личными предпочтениями Кольчужкина, но и его издательской интуицией, выработанной за годы работы в библиотеке им. Пушкина, где он долгое время был занят в секторе депозитарного хранения, читал лекции, формировал списки рекомендуемых для чтения публикаций в периодике, участвовал в телевестнике «Книга», а также приобретал опыт общения с томской научной интеллигенцией. Именно библиотека как важная составляющая изда-

\footnotetext{
${ }^{1}$ См. ниже «Интервью с Е.А. Кольчужкиным».
} 
тельства «Водолей» способствовала становлению и развитию этого авторского проекта, предоставляя свое помещение и фонды. Сам Кольчужкин в личных интервью отмечает, что без поддержки библиотеки «Водолей», скорее всего, не состоялся бы.

Говоря о репертуарной политике издательства, необходимо отметить, что изначально в издательстве стремились выпускать книги, которые когда-то были впервые напечатаны символистами. В этой связи начальный период деятельности «Водолея» можно назвать периодом переизданий, который являл собой совершенно новый продукт как для самого издательства, так и для книжного рынка Томска, представляя уникальный результат проекта. Так, стали издаваться произведения К. Эрберга, И. Коневского, В. Пяста и В. Шилейко. Были опубликованы три зарубежные книги Д. Мережковского и его драматургия, проза Ф. Степуна и статьи К. Мочульского, книга Н. Бердяева о Хомякове и пушкиниана М. Гершензона, воспоминания кн. Е. Трубецкого и уложенный в два переплета «шиповниковский» шеститомник Л. Шестова. В «Водолее» также выходили различные переводные издания, труды по философии (например, «Стихотворения. Истории о Господе Боге» Р.М. Рильке, «Система мировых эпох» Ф.В.Й. Шеллинга и «Пролегомены к истории понятия времени» М. Хайдеггера) [5]. Издательство работало и на заказ. Именно это приносило ему основной доход, на средства которого печаталась основная культурная продукция. В качестве главного канала распространения изданий выступал магазин-салон «19 октября» в Москве. Тем не менее, являясь научным и культурным городом, Томск все же не мог покрыть все издержки производства и принести издательству необходимую известность.

Книги такой узкой тематики, рассчитанные на читателяинтеллектуала, просто не могли быть полностью реализованы на периферии. В итоге такое сотрудничество с Центром стало первым шагом на пути продвижения издательства в сторону столицы, которое успешно завершилось в 2002 г. Это было необходимым решением для его дальнейшего развития. В Томске не было ни столичных архивов, ни библиотек, не хватало специалистов, которые помогали бы в продвижении проекта не только в пределах города, но и на международном уровне. Миссия издательства, цель, концепция, репертуар не могли быть ограничены территориальными рамками. Поэтому переезд был обусловлен не только наличием в Москве больших 
возможностей для развития, но и необходимостью осуществления «культурного трансфера». Так, у издательства появились новые авторы и партнеры, а сотрудники получили доступ ко многим архивным материалам.

С переездом «Водолея» в Москву его главным редактором стал российский писатель-фантаст, литературовед, поэт и переводчик Е.В. Витковский, выступивший инициатором многих проектов (например, серия «Звезды зарубежной поэзии»). Безусловно, на сегодняшний день он является полноправным участником авторского проекта Кольчужкина, который, в свою очередь, уже постепенно становится командным. Именно Витковский как лауреат нескольких международных премий, эксперт Союза переводчиков России, член Союза писателей помог издательству выйти на новый профессиональный уровень, расширить репертуар и культурно-экономические связи.

В Москве издательство сохранило прежнее направление деятельности (серии «Серебряный век. Паралипоменон» и «Малый Серебряный век»), однако появились и новые издательские проекты. Например, стала издаваться современная русская поэзия, ориентированная на классическую традицию: Н. Мальцева, Л. Латынин, С. Шестаков, Е. Чигрин. В этот список вошли и русские авторы, живущие за границей: Н. Басовский, М. Дынкин и Ф. Чечик (Израиль), С. Магид (Чехия), Д. Паташинский, Е. Тверская и Г. Русаков (США), М. Сафонов (Швеция), М. Цесарская (Венгрия) [1].

В связи с этими процессами практически произошла и реализация «культурного трансфера». «Водолей», выполняя функции посредника в процессе передачи культурных артефактов, явился во многом уникальным вариантом разнонаправленного региональноевропейского «трансфера» [6].

Как было сказано выше, культурная коммуникация издательства с Центром началась еще в Томске, но к моменту переезда издательства в столицу у него уже сформировалась мощная культурная база, что дает возможность говорить о реализации «трансфера» уже в двух направлениях по следующей модели: 


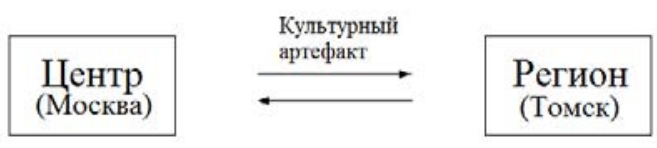

Однако вскоре после переезда данная модель подверглась существенной модификации. Это было связано с тем, что «Водолей» начал сотрудничать с русскими авторами, проживающими за границей, а также с Пизанским университетом, совместно с которым стали выпускаться серии «Русская Италия», «Классики поэтического перевода». Так, межкультурная коммуникация приобрела новые направления, и на сегодняшний день она реализуется следующим образом:
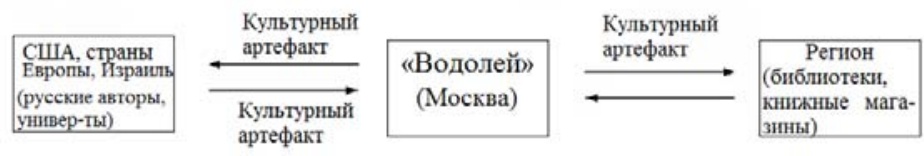

При этом периферия уже выступает участником процесса peųenции, т.е. восприятия культурных артефактов. Например, если в первый период существования «Водолея» томские библиотеки и томский читатель содействовали процессу передачи культурных артефактов (изданий в их культурном, историческом и эстетическом контекстах), то с переездом издательства в Москву роли изменились. Вместе с этим, к сожалению, резко ограничился доступ издательской продукции к ее потребителю. Сегодня книги «Водолея» поступают только в Научную библиотеку ТГУ, и ознакомиться с ними может только узкий круг читателей.

Таким образом, осуществление межкультурной коммуникации является безусловным признаком авторского проекта. Отсутствие «трансфера» в деятельности издательства приводит к культурному «тупику» и, как следствие, к вынужденному закрытию проекта.

Издательство «Водолей», напротив, стало тем самым культурным опытом для Томска, на который необходимо опираться сегодняшним организациям, которые хотят быть не просто типография- 
ми, обслуживающими частных лиц, а представлять собой издательства в том понимании, которое закреплено в различных словарях и учебниках. Сегодня «Водолей» - это сложившийся бренд, который ассоциируется у читателей с интеллектуальной литературой.

Возникает вопрос, есть ли в Томске подобного рода издательства? Думается, что нет. Издательства при вузах ограничены в свободе действий, немногочисленные частные издательства не выполняют редактуру, печатают тексты в авторской редакции, а это уже своего рода самиздат. Несомненно, Томску не хватает такого мощного издательства, как «Водолей», которое бы отвечало потребностям читателей, а не работало на заказ. Ведь такая форма деятельности - это тупик для продвижения многих изданий. Возможно, в дальнейшем ситуация изменится и появится преемник «Водолея», ведь сегодня, когда Томск так активно развивается и специальность издателя и редактора уже внедряется в вузы, для этого есть все возможности.

\section{Интервью с Е.А. Кольчужкиным}

1. На каких основах было создано издательство (коллектив, техническая база и источники финансирования)?

- Издательство было создано с нуля.

Техническая база - компьютер IBM РС АТ (если кто-нибудь помнит, что это такое). Лазерный принтер появился года через два.

Коллектив - я сам. Плюс бухгалтер, конечно. Гораздо позже появились корректор и наборщик. Но, конечно, не в штате, а на договорной основе.

Источник финансирования: вначале - небольшая материальная поддержка, а однажды - кредит. Но очень скоро - исключительно средства от заказных работ + средства от реализации + гранты.

2. Работали ли Вы с современными на тот момент авторами?

- Да, конечно. Прежде всего, как с авторами-заказчиками. Именно на прибыль от заказов выпускалась основная культурная программа издательства.

3. Сформулируйте, пожалуйста, основной принцип в формировании репертуара. 
- То, что любил больше всего: литература Серебряного века. То, что было запрещено и недоступно в течение семидесяти советских лет. Выпускал книги, которые хотел бы иметь в собственной библиотеке. Друзья-шестидесятники говорили: «Мы на машинке перепечатывали, а ты - на печатном станке».

4. Каковы основные каналы распространения книг?

- Знаменитый на всю страну магазин-салон элитарной книги «19 октября» в Москве.

5. С какими сложностями приходилось сталкиваться издательству?

- Это были:

- недостаток средств;

- отсутствие рядом столичных архивов, библиотек, исследователей;

- недобросовестность некоторых книгопродавцев;

- общеэкономические проблемы страны.

6. Редактировали ли Вы книги? Если да, то есть ли у Вас собственные методы и приемы правки?

- Да, конечно. Особых собственных приемов, пожалуй, не было. Руководствовался советами специалистов издательства ТГУ, которым очень благодарен и по сей день.

7. Что, по Вашему мнению, необходимо издательству (особенно региональному), чтобы быть рентабельным?

- Необходимо следующее:

- хороший издательский портфель с книгами, востребованными читателями;

- профессиональный, минимальный по численности коллектив сотрудников;

- отлаженные каналы сбыта, в частности, наличие партнеров-представителей в Москве и обязательное сотрудничество с интернет-магазинами. me?

8. Залог успешного издательства - как Вы его определи-

- Кроме сказанного выше, это:

- наличие в штате хорошего художника и главного редактора - человека высокой общей культуры;

- интернет-сайт; 


\author{
- разумный, взвешенный подход к работе, без излишних \\ авантюр и рисков.
}

\title{
Лumepamypa
}

1. URL: http://www.vodoleybooks.ru/istoria.html (дата обращения: 10.03.2015).

2. Савенко E.H. Чтение сибиряков в середине 60-х гг. - первой половине 80-х гг. XX в. как выражение общественных настроений «застоя» // Книга в российской провинции: парадигмы и альтернативы книжной культуры Сибири в 60-х годах XX - начале XXI века: сб. науч. тр. Новосибирск, 2005. С. 30-55.

3. Альшевская O.H. Книготорговая отрасль Сибири в контексте российских социальных трансформаций рубежа XIX-XX вв. Новосибирск, 2011.

4. Воропаев В.И. Управление проектами в России / Рос. Ассоц. управл. проектами COBHET. М., 1995.

5. 100 книг издательства «Водолей». 1991-2001: каталог / предисл. Е.А. Кольчужкина. Томск, 2001.

6. Лобачева Д.В. Культурный трансфер: определение, структура, роль в системе литературных взаимодействий // Вестн. Том. гос. педагогического ун-та. 2010. Вып. 8. URL: http://cyberleninka.ru/article/n/kulturnyy-transfer-opredelenie-struktura-rolv-sistemeliteraturnyh-vzaimodeystviy (дата обращения: 10.03.2015).

\section{THE VODOLEY PUBLISHING HOUSE AS AN ORIGINAL PUBLISHING PROJECT.}

Text. Book. Publishing, 2015, 1 (8), 101-110. DOI 10.17223/23062061/8/8

Mikhaylenko Kristina A. «Integral'nyy pereplet» Printing House, Ltd. (Tomsk, Russian Federation).E-mail:_bibi@@inbox.ru

Keywords: project, regional publishing house and publisher, Tomsk environment.

The article analyzes the possibility of integration of the project category in the field of book publishing, which involves the study of the relevant theoretical framework and experience of Tomsk book publishing, as well as the development of the concept of an original publishing project. The relevance and novelty of the work consists in referring to the activities of the Tomsk publisher E.A. Kolchuzhkin in the context of the project category.

At the end of the 20th century, in spite of the intricate economic and political processes, the book continues to be an integral part of people's lives. Fiction was the priority. Books about the Great Patriotic War and the so-called entertaining literature were second and third popular. Edition on socio-political topics, historical and memoir works, special literature and books on philosophy were also in demand. It was at this time that the original project of Kolchuzhkin, similar to the central Russia projects of the publishing houses "Vagrius", "Zakharov" or "Slovo", appears. Vodoley was an example of an original multiproject in a regional environment; its subprojects were united by a single concept, themes, mission and time. In this sense Kolchuzhkin's project is a concept that brings together all the works he published. Mission, aim, cultural experience - all these contributed to its implementation. During the country's critical years Vodoley was practically the first private non-state publishing house in a Siberian city. 
The article discusses the repertoire policy, book distribution channels and ways to promote the publishing house in Moscow (the promotion was successfully completed in 2002). When Vodoley moved to Moscow, it was headed by the Russian science fiction writer, literary critic, poet and translator E.V. Vitkovskiy, who initiated many projects. In the capital, Vodoley retained its former publishing activity; new publishing projects were also initiated. For instance, it began publishing contemporary Russian poetry focused on the classical tradition.

Thus, the Vodoley publishing house was the cultural experience in Tomsk that today's publishers must account for, if they do not want to be simple printing houses that serve individuals, but publishing houses in their classical meaning. Today, Vodoley is a formed brand which readers associate with intellectual literature.

\section{References}

1. Izdatel'stvo "Vodoley": terra poetica [Vodoley Publishing House: terra poetica]. Available from: http://www.vodoleybooks.ru/istoria. (Accessed: 10th March 2015).

2. Savenko E.N. Chtenie sibiryakov v seredine $60-\mathrm{kh} \mathrm{gg}$. - pervoy polovine $80 \mathrm{gg}$. XX v. kak vyrazhenie obshchestvennykh nastroeniy "zastoya" [Reading of the Siberians in the mid 60 s - early 80 s of the 20th century as expression of public sentiment of "stagnation"]. In: Posadskov A.L. (ed.) Kniga v rossiyskoy provintsii: paradigmy i al'ternativy knizhnoy kul'tury Sibiri v 60-kh godakh XX-nachale XXI veka [The book in the Russian province: paradigms and alternatives of the book culture in Siberia in the 60-s of the 20th - early 21st century]. Novosibirsk: SB RAS Publ., 2005, pp. 30-55.

3. Al'shevskaya O.N. Knigotorgovaya otrasl' Sibiri $v$ kontekste rossiyskikh sotsial'nykh transformatsii rubezha XIX-XX vv. [Bookselling industry of Siberia in the context of Russian social transformation at the turn of the 20th century]. Novosibirsk: SB RAS Publ., 2011. 330 p.

4. Voropaev V.I. Upravlenie proektami v Rossii [Project management in Russia]. Moscow: Alans Publ., 1995. 225 p.

5. Yakovenko A.V. 100 knig izdatel'stva "Vodoley". 1991-2001 [100 books from Vodoley Publishing House. 1991-2001]. Tomsk: Vodoley Publ., 2001. 63 p.

6. Lobacheva D.V. Cultural transfer: definition, structure and function in literary interactions. Vestnik Tomskogo gosudarstvennogo pedagogicheskogo universiteta - Bulletin of Tomsk State Pedagogical University, 2010, no 8. Available from: http:// cyberleninka.ru/article/n/kulturnyy-transfer-opredelenie-struktura-rol-v-sistemeliteraturnyhvzaimodeystviy. (Accessed: 10th March 2015). (In Russian). 